\title{
Hiring Freeze and Bankruptcy in Unemployment Dynamics
}

\author{
Pietro Garibaldi* \\ University of Turin
}

January 26, 2006

\begin{abstract}
This paper proposes a matching model that distinguishes between job creation by existing firms and job creation by firm entrants. The paper argues that vacancy posting and job destruction on the extensive margin, i.e. from firms that enter and exit the labour market, represents a potentially viable mechanism for understanding the cyclical properties of vacancies and unemployment. The model features both hiring freeze and bankruptcies, where the former represents a sudden shut down of vacancy posting at the firm level with labour downsizing governed by natural turnover. A bankrupt firm, conversely, shut down its vacancies and lay offs its stock of workers. Recent research in macroeconomics has shown that a calibration of the Mortensen and Pissarides matching model account for 10 percent of the cyclical variability of the vacancy unemployment ratio displayed by U.S. data. A calibration of the model that explicitly considers hiring freeze and bankruptcy can account for 20 to 35 percent of the variability displayed by the data.
\end{abstract}

- Key Words: unemployment dynamics, matching models

- JEL Classification: J30

*IGIER, CEPR, IZA. I am indebted to Etienne Wasmer for several insightful and helpful conversations. I also benefitted from discussions with Giuseppe Bertola, Chris Pissarides and seminars participants at the Macro Workshop at the LBS. email: pietro.garibaldi@unito.it 


\section{Introduction}

The matching model of unemployment, or the Mortensen Pissarides (hereafter MP) (1994) model, is generally recognized as the benchmark macroeconomic model of the labor market. A recent debate has challenged the ability of the MP model to capture the key business cycle properties of the U.S. labour market. Shimer (2005a) has argued that a calibration of the model can hardly match the key business cycle facts. Notably, the vacancy unemployment ratio in the U.S. data features a time series variability that is an order of magnitude larger than what a reasonable calibration of the model would predict.

Shimer (2005a) and Hall (2005a), among others, have argued that the main problem of the MP model is the large response of wages to business cycle fluctuations. Wages absorb most of the productivity fluctuations and prevent vacancy and job creation to adequately respond to business cycle fluctuations. Yet, a solution of the model with a fixed wage does not really solve the problem. Mortensen and Nagypal (2005) have shown that the key issue is not wage variability, but rather the level of the average wage vis-à-vis the average productivity. Mortensen and Nagypal (2005) consider also the role of on the job search and capital costs and show that an extended model can account for roughly 40 percent of the variability displayed by the data.

A theoretical shortcoming of the MP model is its inability to proper distinguish between well defined firms and jobs. In the baseline model all firms have only one job. As a result there is no role for job destruction and vacancy posting by firm entry and exit as distinguished by job creation and destruction by existing firms. At the macroeconomic level, job creation and job destruction accounted for by firm entry and exit is well documented, and accounts for 3.8 percent of total employment (Business Employment Dynamics, 2004). The quantitative question addressed in this paper concerns the macroeconomic implications, in terms of aggregate vacancy unemployment volatility, of considering job flows on the firms' extensive margin.

This paper proposes a matching model of the labour market that distinguishes between job creation by existing firms and job creation by firm entrants. It builds on the matching model with large firms initially proposed by Bertola Cabalero (1994), and further analysed by Bertola Garibaldi (2001) and Cahuc et al. (2005). While firms produce with a constant returns to scale technology, their long run dimension is bound by a convex hiring technology. Exogenous job destruction, in the form of worker natural turnover, ensures that firms continuously post vacancies. The comparative static predictions of the steady state equilibrium of the model are very similar to the standard Pissarides matching model (1987). Further, the model converges to a standard matching model as the convex vacancy costs converge to a linear cost structure.

The paper argues that vacancy posting and job destruction on the extensive margin, i.e. from firms that enter and exit the labour market, represents a potentially viable mechanism for understanding the cyclical properties of the vacancy unemployment fluctuations. In the aftermath of positive aggregate shocks, incumbents firms immediately increase their vacancy posting behavior. This increase in job creation by existing firms is akin to the increase in job creation in the standard matching model. Yet, the model predicts 
that alongside the bulk of insider firms there is a margin of highly volatile firms. Such firms act mainly on the extensive margin of firm entry and exit. Following a positive aggregate productivity shock new firms will enter the market and, on impact, will post a discrete mass of vacancies to satisfy their medium run employment position. Thereafter, they grow slowly to their desired employment position. In the aftermath of negative shocks, a positive mass of firms immediately shut down their vacancy posting, inducing a well defined hiring freeze. Whether such firms shed labour and declare bankruptcy depends on the structure and size of wasteful firing costs. In equilibrium it may well be optimal for some firms to operate under hiring freeze, let dismissal be regulated by natural turnover and vacancy posting postponed to periods of favorable business conditions.

The vacancy posting and job destruction induced by these marginal firms is novel to the literature. In the set of simulations proposed, the paper starts from a simple characterization of the Shimer result. Without considering hiring freeze or bankruptcy, the model accounts for 10 percent of the total variability of the vacancy unemployment ratio. Explicitly considering job flows on the extensive margin increases the amplification power of the model. Specifically, a simulation of the model with firm entry and exit accounts for at least 20 percent of the aggregate volatility displayed by U.S. data, and increases to 30 percent in an economy with widespread hiring freeze.

The paper proceeds as follows. Section 2 describes the basic environment. Section 3 describes hiring and firing at the firm level and characterizes bankruptcy and hiring freeze. Section 4 defines and characterizes the general equilibrium of the model and its global stability. Section 5 presents the calibration and the baseline simulations, while section 6 discusses the calibration with firm entry and exit. Section 7 discusses our results and compares the results to those in the literature. Section 8 concludes.

\section{Basic Environment}

- There is a mass one of homogeneous labor. Workers can be in two states, employed or unemployed. Labour is the only factor of production.

- Employed workers are subject to natural turnover. We assume that each worker has a probability equal to $\rho$ of experiencing a turnover shock that force he or she to leave the job and entering into unemployment

- There are $I$ types of firms which we indicate with $i=1$..I. We indicate with $m^{i}$ a measure of the mass of firms of type $i$. One can think of $\sum m^{i}=M$ as a measure of the stock of entrepreneurial ideas in the economy. Not all types of firms are necessarily active at all times. Whenever it is optimal for the firm to produce, the firm uses a constant returns to scale technology and the productivity is indicated with $\eta^{i}+p^{j}$. 
- $\eta^{i}$ is the firm specific productivity value. We we assume that $\eta^{i+1}>\eta^{i}$ Firms with larger idiosyncratic component $\eta^{i}$ have larger labor productivity and larger size in equilibrium.

- $p^{j}$ is an aggregate parameter common across firms and refers to the aggregate state of the economy. There are $j^{\max }$ possible macro states and we assume that $p^{j}>p^{k}$ whenever $j>k$. The probability of a state switch is governed by a Poisson process and we indicate with $\lambda_{j k}$ the instantaneous arrival rate of the shock. Conditional on a shock $\lambda_{j k}$, the state of the economy switches from state $j$ to state $k$ according to a Markov chain with general probability $\sigma_{j k}$ and such that $\sigma_{j j}=0$ and $\sum_{k=1}^{j^{\max }} \sigma_{j k}=1$.

- We shall indicate with $m^{i} l_{t}^{i j}$ the size of workers employed in firms of type $i$ when the state of the economy is $j$.

- Whenever it is optimal to operate a firm and to post vacancies, the filling of jobs is both costly and time consuming. This makes the model perfectly in line with the mainstream matching literature and the MP model. The probability that a vacancy is filled is indicated with $q_{t}^{j}$ where $j$ refers to the state of the economy and $t$ is a pure time index.

- The main departure from the standard MP model concerns the structure of vacancy costs. We follow Bertola and Caballero (1994) and Bertola and Garibaldi (2001) and assume that vacancy posting is regulated by a convex technology, so that the marginal vacancy posting for firm $i$ in state $j$ is $c v_{t}^{i j}$

- Each firm takes as given the probability of filling in a vacancy $q_{t}^{j}$, or the job filling probability as it is labeled in the paper. In the aggregate economy, the probability $q_{t}^{j}$ is described by an aggregate matching function that depends on the aggregate number of vacancies and the stock of unemployed. Its formal expression reads

$$
q_{t}^{j}=\left(\frac{\gamma V_{t}^{j}}{U_{t}^{j}}\right)^{-\alpha}
$$

where $V_{t}^{j}=\sum_{i} m^{i} v_{t}^{i j}$ is the aggregate measure of vacancies and $v_{t}^{i j}$ are the vacancies posted by firm $i$ when the state of the economy is $j . U_{t}^{j}$ is the stock of unemployed and $\gamma$ is simply an efficiency parameter. $\alpha$ is the matching elasticity of $q_{t}^{j}$ with respect to the aggregate vacancy unemployment ratio and varies strictly between 0 and 1

- Over and beyond the exogenous turnover $\rho$ we assume that firing is instantaneous but requires a wasteful separation cost equal to $-F$. While the existence of $F$ is important for modelling a pure hiring freeze, the model works perfectly well with $F=0$.

- We assume that wages are constant across firms and over time, and we indicate their value to $w$. We discuss the importance of this assumption in Section 7 for the business cycle properties of the model, and in the Appendix we solve a steady state version of the model with endogenous wages. 


\section{Hiring and Firing at the Firm Level}

In what follows we indicate with $A_{t}^{i j}$ the marginal shadow value of a vacancy to a firm of type $i$ in state $j$ and with $J_{t}^{i j}$ the marginal shadow value of operating labor. The value of a vacancy reads

$$
r A_{t}^{i j}=-c v_{t}^{i j}+q_{t}^{j}\left[J_{t}^{i j}-A_{t}^{i j}\right]+\sum_{k=1}^{j^{\max }} \lambda_{j k}\left\{\operatorname{Max}\left[A_{t}^{k i}, 0\right] \sigma_{i k}-A_{t}^{i j}\right\}+\dot{A}_{t}^{i j}
$$

The previous equation is similar to the standard asset value function for a marginal vacancy in the matching model, with the only notable key difference that the marginal cost of vacancy posting is increasing in the number of vacancies. The probability of filling a vacancy $\left(q_{t}^{j}\right)$ does not depend on firm characteristics but simply on the state of the economy $j$, which each firm takes as given. Conditional on a macroshock $\lambda_{j k}$ the firm obtains the value of a vacancy in state $k$. Since shutting down vacancy is costless the expression inside the brackets features a max operator, with firms that post vacancies as long as $A_{t}^{k i}$ is strictly positive. If the firm posts at all time the optimal number of vacancies it must be true that $A_{t}^{i j}=\dot{A}_{t}^{i j}=0$ for all $i$ and $j$ so that

$$
c v_{t}^{i j}=q_{t}^{j} J_{t}^{i j}
$$

This is one of the key equations of the model and it simply says that the marginal cost of posting $v_{t}^{i j}$ vacancies is equal to expected marginal benefit, where the latter is the product of the filling probability and the marginal shadow value of labour. The expression of the marginal shadow of labour is

$$
r J_{t}^{i j}=\eta^{i}+p^{j}-w+\rho\left[A_{t}^{i j}-J_{t}^{i j}\right]+\sum_{k=1}^{j^{\max }} \lambda_{j k}\left\{\operatorname{Max}\left[J_{t}^{i k},-F\right] \sigma_{i k}-J_{t}^{i j}\right\}+\dot{J}_{t}^{i j}
$$

The previous expression deserves few comments. The marginal shadow value of labour depends linearly on the operative profits $\eta^{i}+p^{j}-w$. This is not surprising as long as the firm operates with a constant returns technology. Because of natural turnover the firm loses each unit of labour at rate $\rho$ and experiences an aggregate shock at rate $\lambda_{j k}$. Conditional on the aggregate shock $\lambda_{j k}$ the firm needs to decide whether continuing production is optimal at the new value $J_{t}^{i k}$. Shutting down the job requires a wasteful firing cost equal to $-F$.

Once one realizes that the marginal value of vacancy is zero at all time, the shadow marginal value of labour does not depend on the number of vacancies $v_{t}^{i j}$, on the actual employment level $l_{t}^{i j}$ and on the aggregate state contingent matching probability $q_{t}^{j}$. This suggests that the shadow value of a filled labour is time invariant and thus $\dot{J}_{i j}=0$. This result makes the computation and derivation of the equilibrium extremely simple. In what follows we suppress the subscript $t$ to the firm value function.

The value of the marginal job $J^{i j}$ fully describes the firm hiring and firing policy. In general, as long as the shadow value of labour is positive, i.e. $J^{i j}>0$, the firm operates and posts a positive amount of vacancies. Indeed, we call a firm with positive $J^{i j}$ a fully operative firm. Formally, the job creation condition of equation (1) shows that the number of vacancies posted is proportional to the value of $J^{i j}$. Intuitively, 
an increase (decrease) in productivity that leads to an increase (decrease) in $J^{i j}$ leads to an increase in the number of vacancies posted while a negative shock leads to a contraction in the number of vacancies. Yet, as long as $J^{i j}>0$ is positive the firm posts vacancies. In formula, this reads

$$
v_{t}^{i j}=\left\{\begin{array}{cc}
\frac{q_{t}^{j} J^{i j}}{c} & \text { if } J^{i j}>0 \\
0 & \text { if } J^{i j} \leq 0
\end{array}\right.
$$

Things are more complicated when the value of a firm, in the aftermath of a productivity shock, turns negative. First, whenever $J^{i j}<-F$ the firm fires immediately all its employees and does not operate. The firm is bankrupt and the corresponding entrepreneurial idea $i$ is idle. Thus, a firm that was previously operative and sudden experiences $J^{i j} \leq-F$ fires all its workers and declares bankruptcy. Conversely, whenever $0 \geq J^{i j}<-F$ the firm has incentives to stay in operation. Such firm freezes hiring, does not fire its workforce and downsize its workforce thorough the natural turnover $\rho$. This suggests that employment dynamics is described by the following differential equations

$$
i_{t}^{i j}=\left\{\begin{array}{cc}
q_{t}^{j} v_{t}^{i j}-\rho l_{t}^{i j} & \text { if } J^{i j}>0 \\
-\rho l_{i j, t} & \text { if } 0 \geq J^{i j}>-F \\
0 & J^{i j} \leq-F
\end{array}\right.
$$

where $\dot{l}_{t}^{i j}$ is the dynamics of employment at the firm level. Whenever it is optimal to operate, that is whenever $J^{i j}>0$ firm employment dynamics is denoted by the difference between job creation and job destruction. Job destruction at the firm level is driven by exogenous worker quits. Job creation is derived by the vacancy posting behavior and it is indicated with $q_{t}^{j} v_{t}^{j}$. No vacancy posting takes place when $J^{i j}$ is negative and employment is either zero (in the case of bankruptcy) or decline with natural turnover (in the case of natural turnover).

The previous expression allows us to formally define employment dynamics.

Definition 1 Firm employment dynamics features a hiring freeze whenever the firm does not post any vacancy and does not replace departing workers. The firm is bankrupt whenever does not post any vacancy and does not hire any worker. The firm is fully operative whenever it posts vacancies and replaces departing workers.

Making use of the optimal vacancy posting behavior of equation (1), employment dynamics of a firm that is posting vacancy is

$$
i_{t}^{i j}=\frac{\left(q_{t}^{j}\right)^{2} J^{i j}}{c}-\rho l_{t}^{i j} \quad \text { if } J^{i j}>0
$$

Proposition 2 Optimal hiring and firing of a type $i$ firm is described by $t$-ple $\omega_{t}^{i j}=\left\{J^{i j}, v_{t}^{i j}, l_{t}^{i j}\right\}$ that specify a set of value function $J^{i j}$, a vacancies $v_{t}^{i j}$, employment $l_{t}^{i j}$ that satisfy $\left.i\right)$ optimal vacancy posting (equation 2) and ii) optimal employment dynamics (equation 3). 
We can discuss at this stage an important equilibrium feature of the firm value function. The solution to the firm problem is obtained by the functional equation

$$
J^{i j}=\frac{p^{j}+\eta^{i}-w+\sum_{k=1}^{j_{\max }} \operatorname{Max}\left[J_{t}^{i k},-F\right] \sigma_{i k}}{r+\lambda_{j k}+\rho}
$$

where it appears that the job value function is proportional to the productivity $p^{j}+\eta^{i}$. The following remark applies

Remark 3 Bankruptcy and Hiring Freeze are more likely in worse business conditions (lower j) and in firms with lower idiosyncratic component (lower $i$ ).

The model is completed by the workers' asset equations, which nevertheless do not play any specific role in the model with exogenous and fixed wage $w$. If we indicate with $W_{t}^{i j}$ the value to a worker of being in

firm $i$ and with $B_{t}^{j}$ the value of unemployment when the state of the economy is $j$, the value of a job to a worker in firm $i$ reads

$$
r W_{t}^{i j}=w+\rho\left[B_{t}^{j}-W_{t}^{i j}\right]+\sum_{k=1}^{j^{\max }} \lambda_{j k}\left\{\left[\phi^{i k} W_{t}^{i k}+\left(1-\phi^{i k}\right) B_{t}^{k}\right] \sigma_{i k}-W_{t}^{i j}\right\}+\dot{W}_{t}^{i j}
$$

where $w$ is the wage rate and $\phi^{i k}$ is an indicator function that takes the value of 1 if a firm $i$ keeps the job open in the aftermath of a macroeconomic shock from state $j$ to state $k$. Finally, the value of unemployment reads

$$
r B_{t}^{j}=b+\frac{V_{t}^{j}}{U_{t}^{j}} q_{t}^{j}\left[\sum_{i}\left(\frac{m^{i}}{M_{t}^{j}}\right) W_{t}^{i j}-B_{t}^{j}\right]+\sum_{k=1}^{j^{\max }} \lambda_{j k}\left\{B_{t}^{k} \sigma_{i k}-W_{t}^{i j}\right\}+\dot{B}_{t}^{j}
$$

where $b$ is a specific unemployed income, $M_{t}^{j}$ are the cumulative ideas/firm that are active in state $j$ and $\frac{V_{t}^{j}}{U_{t}^{j}} q_{t}^{j}$ is the job finding probability for an unemployed worker when aggregate conditions are $j$. Note that the workers' asset equations, and particularly the value of unemployment $B_{t}^{j}$ do depend on the state of the economy and on the job filling rate $q_{t}^{j}$, so that the pure time derivative is necessarily present in equation 5 .

\section{Aggregate State Contingent Steady State and General Equilib- rium}

As we indicate with $m^{i} l_{t}^{i j}$ the number of workers in firm of type $i$, the allocation of workers across state is

$$
U_{j}+\sum_{i=1}^{I} m^{i} l_{t}^{i j}=1
$$

where $U_{j}$ is aggregate unemployment when the state of the economy is $j$

One can think of an aggregate state contingent equilibrium as a situation in which the economy would eventually settle if there were no more changes in aggregate productivity (Rogerson Pries, 1998). This 
means that in an aggregate state contingent equilibrium vacancy posting and total employment at each firm $i$ are constant and so is aggregate unemployment. For a firm for which operating is optimal, employment is constant whenever there is no aggregate shock and the number of vacancies posted is identical to job destruction induced by natural turnover.

Definition 4 In an aggregate state contingent steady state all time varying variables are constant.

When employment in each firm $i$ is constant, job creation is equal to job destruction at the firm level and employment in firm of type $i j$ is

$$
l^{i j}=\frac{\left(q^{j}\right)^{2} J^{i j}}{\rho c} \quad \forall J^{i j}>0
$$

where the state state variables are not indexed by time to indicate that are constant in steady state. The measure of vacancies in each hiring firm is

$$
v^{i j}=\frac{q^{j} J^{i j}}{c} \quad \forall J^{i j}>0
$$

Unemployment in state of the economy $j$ is

$$
\begin{aligned}
U_{j} & =1-\sum_{i} m^{i} l_{i j} \\
U_{j} & =1-\sum_{i} m^{i} \frac{q^{j 2} J^{i j}}{\rho c} \quad \forall J^{i j}>0
\end{aligned}
$$

where the latter equation made use of the vacancy posting in firm $i j$ of equation (6). The aggregate number of vacancies in each state is

$$
V_{j}=q^{j} \frac{\sum_{i} m^{i} \operatorname{Max}\left[J^{i j}, 0\right]}{c}
$$

where the max operator is consistent with the fact that vacancies are posted only in firms with positive value functions $J^{i j}$. An aggregate equilibrium is a value of $q^{j}$ consistent with the value assumed at the firm level in their hiring and firing decision. Formally, the aggregate definition of $q^{j}$ must satisfy the following consistency requirement

$$
\begin{aligned}
q^{j} & =\left(\frac{\gamma V_{j}}{U_{j}}\right)^{-\alpha} \\
\left(q^{j}\right)^{-\frac{1}{\alpha}-1} & =\frac{\gamma \sum_{i} m^{i} \frac{\operatorname{Max}\left[J^{i j}, 0\right]}{c}}{1-\left(q^{j}\right)^{2} \sum_{i} m^{i} \frac{\operatorname{Max}\left[J^{i j}, 0\right]}{\rho c}} \\
\left(q^{j}\right)^{\frac{1+\alpha}{\alpha}} & =\frac{\rho-k^{j}\left(q^{j}\right)^{2}}{\gamma k^{j} \rho}
\end{aligned}
$$

where we define the constant $k^{j}$ as

$$
k^{j}=\sum_{i: J^{i j}>0} m^{i} \frac{J^{i j}}{c}
$$


so that only hiring firms are considered in equation (10). The constant $k^{j}$, which records the set of parameters and functions that vary with the aggregate state will play a key role in the dynamic analysis of the next sections.

Definition 5 An aggregate state contingent equilibrium in state $j$ is a set of value functions $J^{i j}$, $A^{i j}$, employment level $l^{i j}$, vacancies $v^{i j}$ and a value of the job filling rate $q^{j}$ that satisfy

- optimal vacancy posting

- optimal employment

- steady state employment

- aggregate consistency in $q^{j}$

We are already in a position to proof the following proposition

Proposition 6 An aggregate state contingent equilibrium with positive $q^{j}$ exists and it is unique if and only if $k^{j}>0$

Proof. To proof the uniqueness of the equilibrium it suffices to study the slope of the r.h.s and the l.h.s of equation (10). The l.h.s side is a monotonically increasing convex function of $q^{j}$ that crosses the origin. The r.h.s. is a parabola with a maximum at $\left(\frac{k^{j}}{\gamma}\right)^{1 / 2}$. The key condition for uniqueness and existence is that the parabola displays positive values in the origin, or that $k^{j}>0$, which is simply a condition for a viable labor market, in the sense that it ensures that a positive number of vacancies is posted in equilibrium.

The solution of the equilibrium works as follows. First, from equation (4) the set of value functions $J^{i j}$ is obtained. Next, the general equilibrium value of $q^{j}$ is derived by equation (10). Finally, once the job finding rate is determined, equilibrium unemployment is determined by equation 7 and the aggregate number of vacancies is given by equation (8).

The aggregate model features a negative relationship between the unemployment rate and the stock of vacancies, or a Beveridge curve as it is typically known in the literature. Formally, in steady state unemployment is constant if inflows are equal to outflows or

$$
\rho\left(1-U^{j}\right)=\frac{V^{j}}{U^{j}} q^{j} U^{j}
$$

where $\frac{V^{j}}{U^{j}} q^{j}$ is the workers' job finding rate. Rearranging one has

$$
U^{J}=1-\frac{q^{j}}{\rho} V^{J}
$$

which is a negative relationship between the unemployment rate and the aggregate stock of vacancies consistent with constant unemployment. 


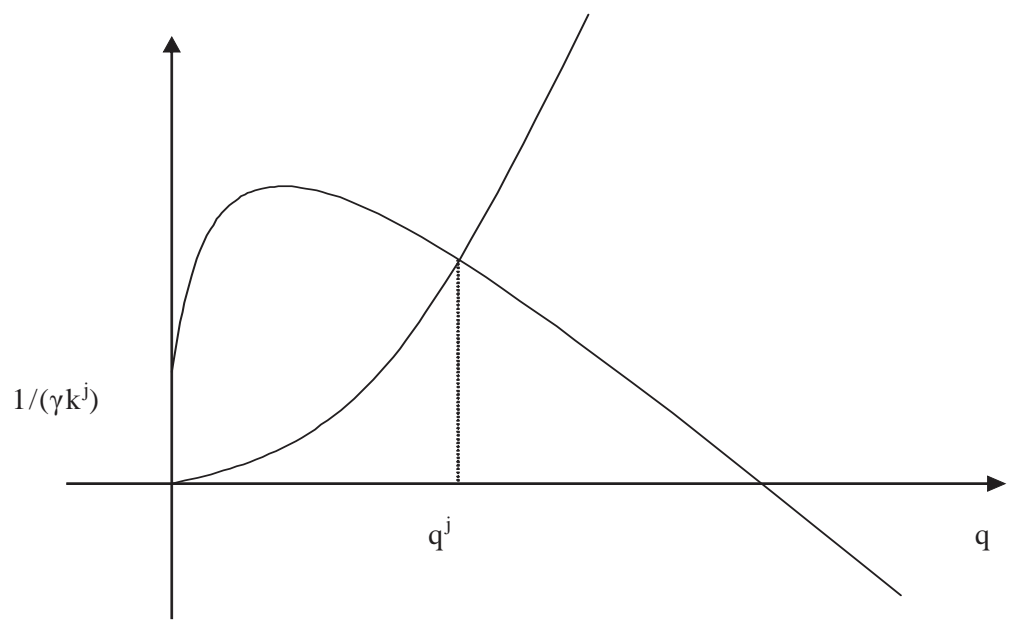

Figure 1: Existence and Uniqueness of an Aggregate State Contingent Equilibrium

\subsection{Basic Comparative Static}

Basic comparative static around the state contingent steady state can easily be performed with respect to the job filling rate. All results are in line with the equilibrium unemployment matching models (Pissarides 1987, 2000), even though in such models the key macro variable is typically market tightness, or the aggregate vacancy unemployment ratio $\frac{V^{J}}{U^{J}}$, a variable that is negatively related to the job filling rate by the matching function. The job filling rate $q^{j}$ depends directly, through equation (10), on the parameters $\rho, \gamma, \alpha$, and $k^{j}$, where $k^{j}$ is it self a function of the rest of the structural parameters at the firm level. In the appendix we report the formal derivation of the comparative static results.

The comparative steady state statistics can be studied graphically under the assumption that there is only one type of firm (i.e $I=1$ ), and that $\lambda$ is equal to zero. In this case the fixed point $q^{j}$ is the solution to

$$
\left(q^{j}\right)^{\frac{1+\alpha}{\alpha}}=\frac{c(r+\rho)}{\gamma m(p+\eta-w)}-\frac{\left(q^{j}\right)^{2}}{\gamma \rho}
$$

Table 1 summarizes the comparative static effects of the key parameters of the model. The effect on the job filling rate is analytically determined, while the effect on the other key macrovariables, notably the unemployment rate, the stock of vacancy and their ratio, is determined by numerical simulations around the steady state calibrated in section [5].

The aggregate productivity $p$ is the key parameter and represents the driving force in our business cycle analysis of the next sections. An increase in aggregate productivity reduces the job filling rate $q^{j}$. Analytically such effect is determined by the positive relationship between $p$ and $k^{j}$ and on the negative relationship of the latter on $q^{j}$ in equation 10, as shown in the appendix. The graphical interpretation 
is obtained from the shifting of the r.h.s of equation 12. The economics works as follows. An increase in productivity increases the marginal value of the job, so that firms' incentive to post new vacancies are higher, thus increasing the vacancy unemployment ratio. In equilibrium, firm competition for hiring unemployed workers increases and each firm finds it more difficult to fill in the new vacancies. The other side of the coin, typical of search market, is that unemployed workers will find jobs more easily. The total effect of aggregate productivity on the unemployment rate is thus the result of two opponent forces: a negative effect through the value of the job $J^{i}$ and a negative effect through the job filling rate $q^{j}$, as it is evident from equation 7. In equilibrium the first effect dominates, so that unemployment is countercyclical vis-à-vis changes in the aggregate productivity. Similar effects are at work for the aggregate vacancy rate.

The parameter $\gamma$ is a pure friction parameter in the matching function, and it thus reduces the job filling rate, the vacancy unemployment rate and increases the unemployment rate.

The discount rate reduces the firm value function and in turns reduces the firm incentives to post new vacancies. In equilibrium the job filling rate is larger, as analytically identified by the negative relationship between $q$ and $k^{j}$ and by the negative effect of the discount rate on $k^{j}$. In turn, the vacancy unemployment rate is lower, unemployment rate is larger and so is the aggregate stock of vacancies.

The effect of the natural turnover rate $\rho$ on the job filling rate is more complicate, since the turnover rate affects $q^{j}$ directly as well as indirectly through the effect of the turnover rate on the parameter $k^{j}$. The latter effect is similar to a larger discount rate on the firm value function while the former is akin to a shift of the Beveridge curve. As shown in the Appendix, the two effects reinforce each other and larger turnover rate $\rho$ reduces the job filling rate. Further, in the aggregate economy unemployment increases and the number of vacancies fall.

When the model features more than one type of firms the conditional steady state displays also a distribution of workers across different firms. In steady state, the proportion of workers in each firm of type $i$ is $m^{i} l^{i j}=\frac{m^{i}\left(q^{j}\right)^{2} J^{i j}}{\rho c}$ and the model features a distribution of employment across firms with each employment size $l^{i j}$ having a weight proportional to the number of firms of type $i$.

Table 1: Comparative Static

\begin{tabular}{|c|c|c|c|c|}
\hline & $q^{j}$ & $\frac{V^{j}}{U^{j}}$ & $U^{j}$ & $V^{j}$ \\
\hline \multicolumn{5}{|l|}{ Parameter } \\
\hline$p$ & - & + & - & + \\
\hline$\rho$ & + & - & + & - \\
\hline$\gamma$ & - & - & + & - \\
\hline$r$ & + & - & + & - \\
\hline$m^{i}$ & + & - & + & - \\
\hline \multicolumn{5}{|c|}{$\begin{array}{l}\text { The effect on } q^{j} \text { is analytically determine } \\
\text { The effect on other variables is based } \\
\text { on simulation of the calibrated economy }\end{array}$} \\
\hline
\end{tabular}




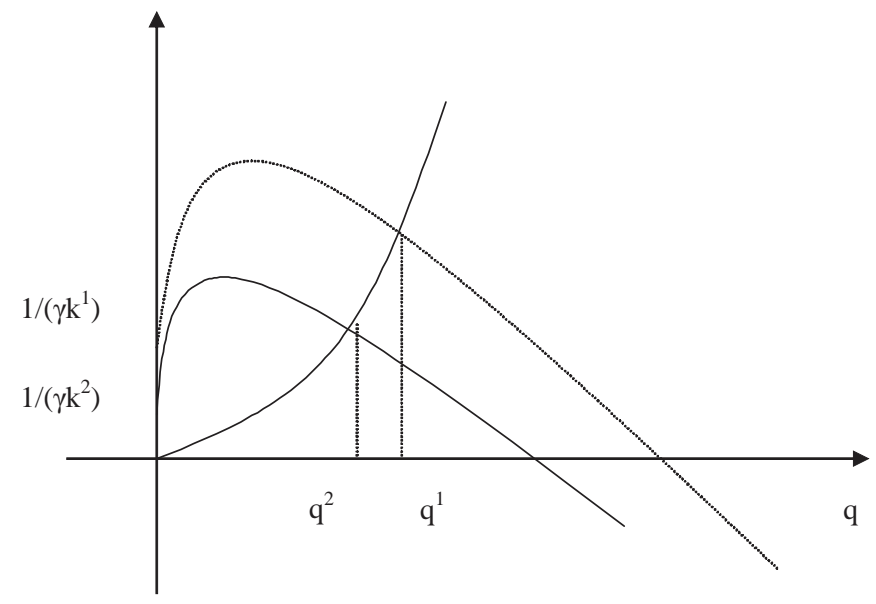

Figure 2: The effects of an increase in productivity $p$

\subsection{Dynamics around the state contingent steady state}

We first consider the economy in state contingent equilibrium $q^{j}$ and ask whether, starting from a general initial value $q_{o}$, the economy converges to the unique value $q^{j}$. Technically the aggregate consistency between $q_{t}^{j}$ at the firm level and in the aggregate economy must hold at all times. So at each point in time it must be true that

$$
\left(q_{t}^{j}\right)^{-\frac{1}{\alpha}}=\frac{\gamma q_{t}^{j} k^{j}}{1-\sum_{i} m^{i} l_{t}^{i j}}
$$

where $k^{j}$ is given by equation (11). After a few steps of Algebra (see Appendix), using the definition of employment dynamics one easily obtains

$$
\dot{q}_{t}^{j}=-\frac{1}{\gamma}\left(q_{t}^{j}\right)^{2-\frac{1}{\alpha}}+\frac{\rho}{\gamma k^{j}}\left(q_{t}^{j}\right)^{-\frac{1}{\alpha}}-\rho q_{t}^{j}
$$

The previous equation is a nonlinear differential equation in $q_{t}^{j}$ which governs the behavior of the aggregate economy given a state $j$. Setting $\dot{q}_{t}^{j}=0$, after a few step of algebra one finds that

$$
\left(q_{t}^{j}\right)^{\frac{1}{\alpha}+1}=\frac{\rho-k^{j}\left(q_{t}^{j}\right)^{2}}{\gamma \rho k^{j}}
$$

which is obviously the steady $q^{j}$ derived in equation (10). The following proposition establish the key result

Proposition 7 The unique state contingent steady state is globally stable

To proof the result write the differential equation as

$$
\dot{q}_{t}^{j}=-\frac{1}{\gamma}\left(q_{t}^{j}\right)^{2-\frac{1}{\alpha}}+\frac{\rho}{\gamma k^{j}}\left(q_{t}^{j}\right)^{-\frac{1}{\alpha}}-\rho q^{j}
$$



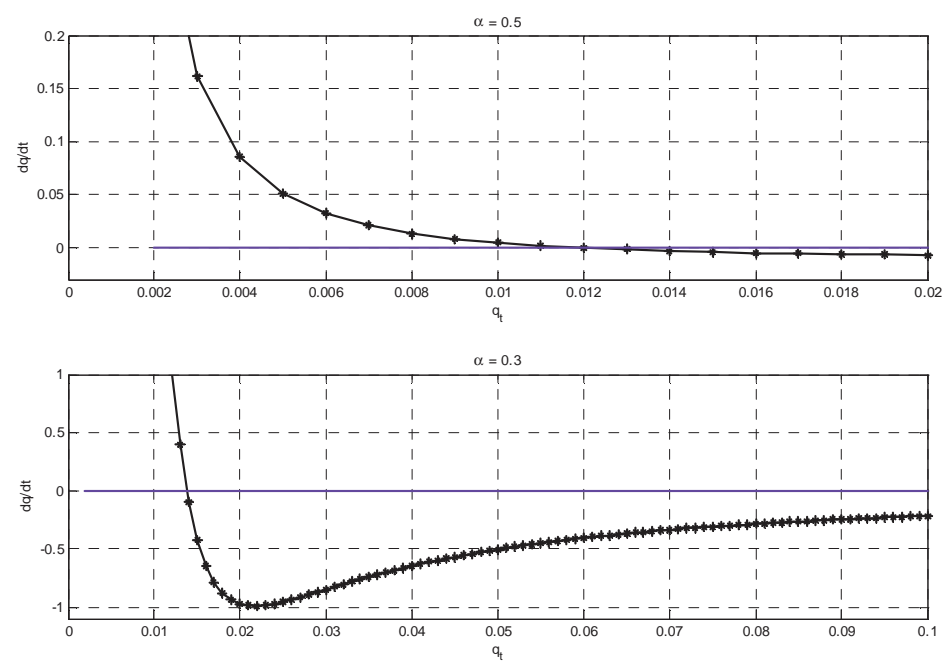

Figure 3: Fundamental Differential Equation for Different Values of $\alpha$

Since $\dot{q}_{t}^{j}$ crosses zero at most once the stability is global. Further, in taking the derivative of the right hand side one has

$$
\frac{\partial \dot{q}_{t}^{j}}{\partial q}=-\left(2-\frac{1}{\alpha}\right) \frac{1}{\gamma}\left(q_{t}^{j}\right)^{1-\frac{1}{\alpha}}-\frac{1}{\alpha} \frac{\rho}{\gamma k^{j}}\left(q_{t}^{j}\right)^{-\frac{1}{\alpha}-1}-\rho
$$

which is definitely negative when $\alpha>\frac{1}{2}$. When $\alpha \leq \frac{1}{2}$ there can be different dynamic acceleration but the global stability is ensured by the uniqueness of the zero. Taking the limit of $\dot{q}_{t}^{j}$ it is immediate to see that $\lim _{q_{t} \rightarrow 0} \dot{q}_{t}^{j}=+\infty$. Figure 3 shows the fundamental differential equation for $\alpha=1 / 2$ and $\alpha=0.3$. In the latter case, the equilibrium is still unique but $\dot{q}_{t}^{j}$ is not monotonic.

\subsection{Business Cycles}

The fundamental differential equation of the model has a unique stable equilibrium but can not be solved analytically. Yet, numerical solutions are easily obtained. ${ }^{1}$ Given an initial condition on the fob filling rate $q_{0}^{j}$, with the solution to the differential equation $q^{j}(t)$ it is possible to to obtain a full dynamic path toward the steady state also for unemployment $U_{t}^{j}$ and the stock of vacancies $V_{t}^{j}$. The system is then described by a $t-$ ple $\Omega_{t}=\left\{p^{j}, q_{t}^{j}, V_{t}^{j}, U_{t}^{j}\right\}$

The stochastic version of the model is represented by fluctuations around different state contingent steady states. The state of the economy is described by the aggregate productivity $p^{j}$, and following a change in state $p^{k}$ the economy will jumps to a new differential equation $q_{t}^{k}$.

In the basic calibration of the next section we work with a stochastic model with two different values $p^{1}$ and $p^{2}$ so that the differential equation is fully characterized by two key constants $k^{1}$ and $k^{2}$. Figure 4

\footnotetext{
${ }^{1}$ The numerical solution of the differential equation is obtained with the ode 23 command in matlab
} 


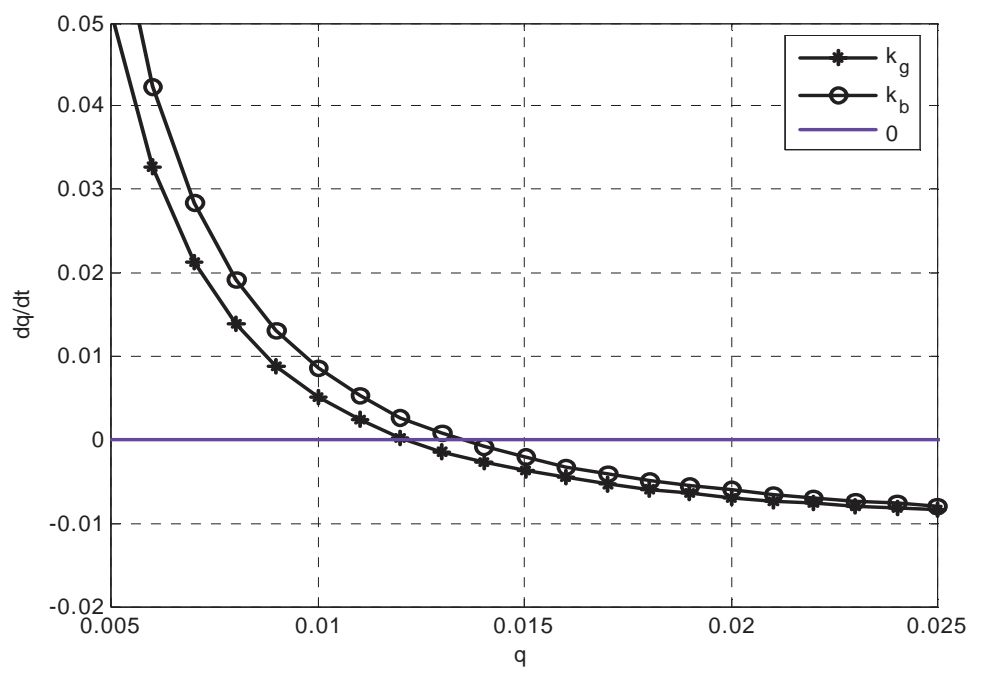

Figure 4: Differential Equation in Good an Bad Times

reports the differential equation in the good state $\left(p^{j}=p^{2}\right.$ and $\left.k=k^{2}\right)$ and bad states $\left(p^{j}=p^{1}\right.$ and $\left.k=k^{1}\right)$. Note that the economy in good times (when $k^{j}=k^{2}$ ) jumps to a lower differential equations and features a lower steady state value of $q^{j}\left(q^{2}<q^{1}\right)$ in line with the comparative static of the previous section.

Figure 5 plots the full path of the economy as the state switches from one state to the other. The convergence is fairly fast, and the system increases (decreases) monotonically as it moves from the good (bad) to the bad (good) state.

\section{Baseline Calibration and Simulation}

The paper focuses on the cyclical properties of the U.S. labour market, as recently summarized by Shimer (2005a). He reports the key cyclical statistics for the six key macro variables in the labour market, namely the unemployment rate, the vacancy rate, the vacancy unemployment ratio, the job finding rate, the separation rate and aggregate productivity. In line with the business cycle literature, all variables are reported in cyclical component, measured as percentage deviation from a smoothing parameter (which is an HP filter with smoothing parameter $10^{5}$ ). The key summary statistics analyzed are the standard deviation and autocorrelation of each cyclical component, and their correlation matrix. The statistics compiled by Shimer are reported in Table 2 and we refer to the original work for the detailed definition of each variable.

Aggregate productivity, which features a standard deviation of 2 percent, is assumed as the driving force in most macromodels of the labour market. Fluctuations in the separation rate are considered a further potential driving source, even though in the current paper we take them as fixed. What is called in the 


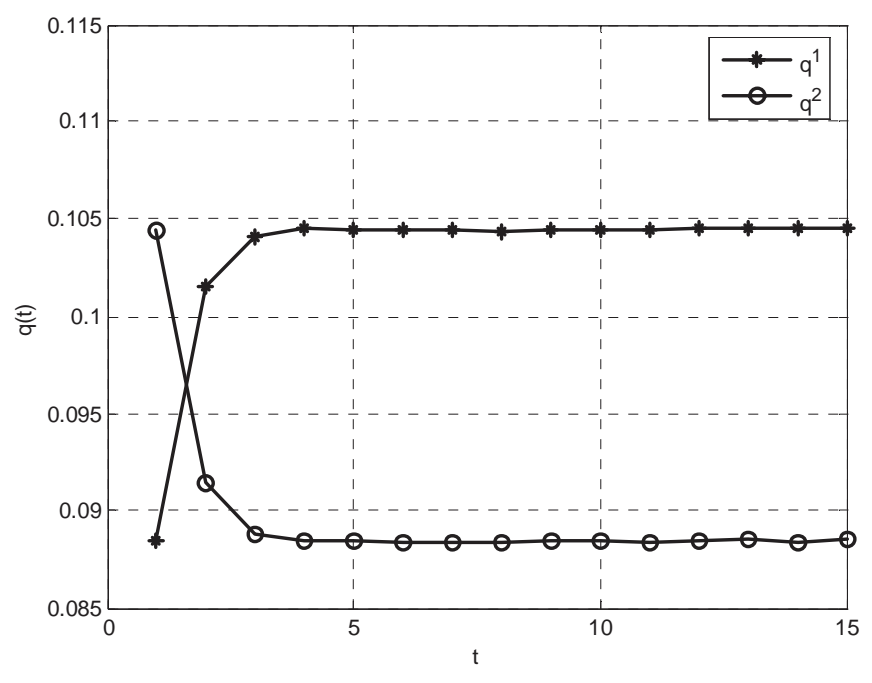

Figure 5: Time profile of $q^{j}(t)$ in good and bad times

literature as the Shimer puzzle is the large volatility of the vacancy unemployment ratio. In the U.S. quarterly time series the $v / u$ ratio features a standard deviation around 40 percent, approximately 20 times larger than the standard deviation of productivity. This suggests that the U.S. labour market features a large degree of amplification of business cycle shocks, and the claim of Shimer is that such amplification power is missing in the baseline matching model. Note that the ratio of the two standard deviations, measured in $\log$ differences around a smooth trend, is also a measure of the elasticity of the vacancy unemployment ratio to productivity changes, and features a value of 19.3. In the real world the vacancy unemployment ratio responds to various shocks so that the empirical elasticity is lower. One way to estimate this is to regress the cyclical component of the $v / u$ ratio on productivity. The result can be read directly from Table 2 , since it is just the ratio of the two standard deviations times their correlation (0.39 in the Table). The value of the elasticity one obtains in this case is thus 7.56.

The baseline calibration that we propose show the strong similarities between the model proposed and the standard matching model. The similarity is particularly strong when the model does not feature any hiring freeze or any bankruptcy. In other words, we base our initial calibration to an economy with only one type of firm $(I=1)$. Yet, as long as $j^{\max }>1$ the economy is subject to aggregate productivity shocks and it fluctuates around different state contingent steady states. In what follows we show that the model features cyclical properties very similar to the baseline calibration proposed by Shimer (2005a), and indeed fails largely to account for the cyclical variability of the vacancy unemployment ratio.

The calibration is displayed in Table 3. We take the period as representing 1 quarter. The matching function requires to specify two parameters: the matching elasticity $\alpha$ and the matching constant (the 
friction parameter $\gamma$ ). The matching elasticity is a key parameter for the stability of the key differential equation. It is set in Table 3 to 0.5 , a value that is largely recognized in the empirical literature (Petrongolo and Pissarides 2001) as a central value in the range of available estimates. The matching constant is chosen so that the average unemployment rate displayed in the simulation matches the average monthly U.S. unemployment of 5.6 percent over the reference period.

The stochastic process requires setting a value for the average productivity, specifying the number of aggregate states $\left(i . e . j^{\max }\right)$ and their transition rates. For the average productivity level we follow Shimer (2005) and set an average productivity level equal to 1. For the stochastic process, we follow a minimalist approach and we work with only two aggregate states and a fixed transition rate. $\lambda$ is set to 0.02 and the values of $p_{2} p_{1}$ are chosen so that the standard deviation of the cyclical component of productivity in the model generated data (using a smoothing parameter of $10^{5}$ as in the original data) is roughly equal to 0.02 .

The natural turnover rate is 0.9 and is set so as to obtain an aggregate quarterly unemployment inflows consistent with the average statistics compiled by Shimer, which report an average monthly job separation rate equal to 0.0374 . The pure interest rate is set to 0.015 . The firing costs are set equal to zero in the baseline calibration, and take a positive (small) value only when we model hiring freeze in section 6.3.

The fixed wage rate is the most important parameter to set for the model's dynamic properties, as we show in the discussion on the literature in Section 7. In what follows we set a value of the wage equal to 0.75, which induces an amplification of the model similar to the Shimer calibration of the MP model with endogenous wages. Note that the size of the wage determines also the value of operational profits. A value of 0.75 corresponds to sizeable profits and rents from market participation.

The marginal cost of vacancy is equal to 0.7 , so that it represents some 70 percent of flow output. While this number looks high, it has no impact on the calibration of the elasticity of the vacancy unemployment ratio. This feature is well known in the literature, and it is further confirmed in the discussion of Section 7. The value of $c$, and particular the ratio of $c$ to the mass of firms $m$ is important for calibrating the average value of the job filling rate and the job finding rate ${ }^{2}$. While there is no estimate of the job filling rate, the job finding rate is estimated by Shimer, it amounts to a quarterly value of 1.35 . Our calibration is meant to capture this key average statistic. To simulate the model with firm heterogeneity the last parameters to set are the firm idiosyncratic component (the productivity of the representative firm) and the number of firms. $\eta_{2}$ is set to 0 so that the representative firm follows the average productivity. The choice of the parameter $m_{2}$ is set also to target an average vacancy unemployment ratio equal to 1 , a value that is often taken as a reference point.

The simulations are based on [100] repetitions of time series of 500 periods with the first 100 observations

\footnotetext{
${ }^{2}$ The key steady state relationship for $q$ with $\alpha=1 / 2$ and only one type of firms is

$$
\gamma \rho q^{3}+q^{2}=\frac{c}{m} \frac{(r+\rho) \rho}{(p+\eta-w)}
$$
}


that are disregarded to reduce the importance of initial conditions. The simulated statistics are logged and filtered with the same filter parameter of $10^{5}$. The results of the baseline simulations are reported in Table 4 . The standard deviation of productivity is indeed very close to the 2 percentage standard deviation presents in U.S. data. The autocorrelation of the macrovariables is also very high, slightly lower than the actual one mainly because of the autocorrelation displayed by our simple stochastic process.

The model captures well the correlation between unemployment and the other key variables. The negative correlation between unemployment and vacancies, or the Beveridge curve as it is known and presented above, is very much present in the model generated data. The other correlation are also as negative as in the data.

The main failure of the model in Table 4 lies in its inability to match the cyclical standard deviations. With a cyclical variation of aggregate productivity of around 2 percentage point, the cyclical variation of the vacancy unemployment ratio is 0.040 , against a value in the U.S. data of 0.382 . The variability displayed by the model is an order of magnitude lower than what is displayed by the U.S. data. The elasticity of market tightness over employment is indeed 2.0, very similar to Shimer (2005, Table 3). In this sense, the model we propose features the same cyclical characteristics of the baseline matching model with endogenous wages.

As pointed out by Mortensen and Nagypal (2005), and as we argue in the discussion of Section 7, the key issue is not the wage variability per se. The lack of amplification of the model is linked to the large difference between labor productivity and the wage implied by the assigned magnitude of the parameters. In our baseline calibration we have used a "large" difference between average productivity and a fixed wage, so as to obtain results very similar to the baseline calibration of Shimer.

Table 2: Summary Statistics, Quarterly U.S. Data, 1951-2003

\begin{tabular}{|c|c|c|c|c|c|c|c|}
\hline & & $u$ & $v$ & $v / u$ & $f$ & $\rho$ & $p$ \\
\hline Standard Deviation & & 0.190 & 0.202 & 0.382 & 0.118 & 0.075 & 0.020 \\
\hline Quarterly autocorrelation & & 0.936 & 0.940 & 0.941 & 0.908 & 0.733 & 0.878 \\
\hline \multirow[t]{6}{*}{ Correlation Matrix } & $\mathrm{u}$ & 1 & -0.894 & -0.971 & -0.949 & 0.709 & -0.408 \\
\hline & $\mathrm{v}$ & - & 1 & 0.975 & 0.897 & -0.684 & 0.364 \\
\hline & $\mathrm{v} / \mathrm{u}$ & - & - & 1 & 0.948 & -0.715 & 0.396 \\
\hline & $\mathrm{f}$ & - & - & - & 1 & -0.574 & 0.396 \\
\hline & $\rho$ & - & - & - & - & 1 & -0.524 \\
\hline & $\mathrm{p}$ & - & - & - & - & - & 1 \\
\hline \multicolumn{8}{|c|}{$\begin{array}{l}u \text { is the unemployment rate; } v \text { is the vacancy rate } \\
v / u \text { is the vacancy unemployment ratio; } f \text { is the job finding rate } \\
f \text { is the job finding rate; } p \text { is aggregate productivity }\end{array}$} \\
\hline
\end{tabular}


Table 3: Parameter Values in Simulation

\begin{tabular}{|c|c|c|}
\hline Parameter & Notation & Value \\
\hline Interest Rate & $r$ & 0.0150 \\
\hline Natural Turnover & $\rho$ & 0.1000 \\
\hline Search cost & $c$ & 0.7000 \\
\hline Firing cost & $F$ & 0 \\
\hline Matching Function & & \\
\hline Matching Elasticity & $\alpha$ & 0.5000 \\
\hline Matching Constant & $\gamma$ & 0.6600 \\
\hline Stochastic Process & & \\
\hline Fixed Common Productivity & $p$ & 1 \\
\hline Macro states & $j^{\max }$ & 2 \\
\hline Good state & $p_{2}$ & 0.0290 \\
\hline Bad state & $p_{1}$ & -0.0290 \\
\hline Arrival Rate & $\lambda$ & 0.0200 \\
\hline \multicolumn{3}{|l|}{ Fixed Wage } \\
\hline Wage & $w$ & 0.7500 \\
\hline \multirow[t]{3}{*}{ Representative Firm } & & \\
\hline & $\eta_{2}$ & 0 \\
\hline & $m_{2}$ & 0.0200 \\
\hline \multirow{3}{*}{$\begin{array}{l}\text { Heterogeneous Firm } \\
\text { Type of Firms }\end{array}$} & & \\
\hline & $I$ & 2 \\
\hline & $\eta_{1}$ & -0.2600 \\
\hline Source: Authors calculation & & \\
\hline
\end{tabular}

\section{Simulation With Hiring Freeze and Bankruptcies}

We now turn to the model with firm heterogeneity and with turnover on the extensive margin. Before calibrating the model with entry and exit for firms, we review the basic key summary facts of employment gains and losses associated to firm entry and exit

\subsection{Basic Facts on Employment Flows Associated to Firm Entry and Exit}

From the macroeconomic standpoint, the key features of employment gains and losses associated by the process of firm entry and exit can be summarized as follows.

- Average job creation and destruction by firm entry and exit amounts, on average, to 3.8 percent of employment;

- job creation by firm entrants is procyclical while job destruction by firm exit is countercyclical;

- job creation and destruction on the extensive margins take place in firms that are very small relatively to incumbent; 
Table 4: Baseline Simulation

\begin{tabular}{|c|c|c|c|c|c|c|}
\hline \multicolumn{7}{|c|}{$\begin{array}{l}\text { No Hiring Freeze; No Bakruptcies } \\
\mathrm{m} 1=0 ; \mathrm{m} 2=0.0200\end{array}$} \\
\hline & & $u$ & $v$ & $v / u$ & $f$ & $p$ \\
\hline \multirow{2}{*}{\multicolumn{2}{|c|}{ Standard Deviation }} & 0.0148 & 0.0288 & 0.0406 & 0.0163 & 0.0197 \\
\hline & & $(0.0026)$ & $(0.0046)$ & $(0.0065)$ & $(0.0046)$ & $(0.0027)$ \\
\hline \multirow[t]{2}{*}{ Autocorrelation } & & 0.9672 & 0.8675 & 0.9100 & 0.8733 & 0.9065 \\
\hline & & $(0.0112)$ & $(0.0332)$ & $(0.0267)$ & $(0.0320)$ & $(0.0347)$ \\
\hline \multirow[t]{9}{*}{ Correlation } & $\mathrm{u}$ & 1 & -0.7084 & -0.8648 & -0.9889 & -0.7092 \\
\hline & & & $(0.0310)$ & $(0.0227)$ & $(0.0034)$ & $(0.0309)$ \\
\hline & $\mathrm{v}$ & & 1 & 0.9668 & 0.7663 & 0.9994 \\
\hline & & & & $(0.0019)$ & $(0.0213)$ & $(2.1407 \mathrm{e}-004)$ \\
\hline & $\mathrm{v} / \mathrm{u}$ & & & 1 & 0.9021 & 0.9667 \\
\hline & & & & & $(0.0148)$ & $(0.0020)$ \\
\hline & $\mathrm{f}$ & & & & 1 & 0.7630 \\
\hline & & & & & & $(0.0220)$ \\
\hline & $\mathrm{p}$ & & & & & 1 \\
\hline \multicolumn{7}{|c|}{ Standard errors in parentheses } \\
\hline \multicolumn{7}{|c|}{ Average Job Finding Rate $=1.3822$} \\
\hline \multicolumn{7}{|c|}{ Elasticity of $v / u$ with respect to $p=2.0635$} \\
\hline Source: Authors calculat & & & & & & \\
\hline
\end{tabular}

- job destruction (creation) by firm exit (entry) does not exceed 2 percent of total employment in a given quarter;

- entry and exit patterns are highly correlated across industries.

Statistics on firm and entry have been compiled by Davis et al. (1996) for the manufacturing sector and more recently by the Business Employment Dynamics (2004) for the entire U.S. manufacturing industry. Davis et al. provide a fairly large time series (from 1972 to 1988) while the Business Employment Dynamics covers a shorter period (1992-2003), but it is much more reliable in terms of macroeconomic estimates, since employment in manufacturing in the U.S. corresponds to less than 15 percent of total employment. Business Employment Dynamics finds that, on average, firm entry and exit account for 3.8percent of employment.

Employment gains are procyclical and employment losses are countercylical. In other words, firms enter in good times and leave the market in bad times. Business Employment Dynamics (2004) argues that the employment flows driven by entry and exit are less cyclical than those derived by incumbents. This feature can be estimated with the relative long time series compiled by Davis and Haltiwanger (1996). The cyclical correlation of the cyclical component of job creation and destruction and net employment growth is 0.2 for job creation and-0.28for job destruction

The structural characteristics of the process of entry and exit are provided, among others by Bartelsman et al. (2005) and by Dunne et al. (1989). The small size of entrants and exit is clearly documented by 
Bartelsman et al. (2005). They show that the average firm entering and exit the market features an average size that in the U.S. is approximately 10 percent of the employment of incumbent firms.

Despite their cyclical variability, job gains and losses by incumbent firms never exceed 2 percentage of total employment. The 2 percent refers to the cyclically adjusted measure. In cyclically unadjusted data the cyclicality is as high as 2.5 percent.

\subsection{Simulation with Entry and Exit}

We now present the simulation of the model with heterogeneous firms. This section focuses on job flows by firm entry and exit, a process that in the model is obtained by the existence of marginal firms, or by firms whose operation is aggregate state contingent. As it is clear from equation (4) firm entry increases with improvements in aggregate conditions while firm exit is more likely when conditions worsen.

In the example we provide there are only 2 type of firms. Type 2 firms are the incumbent firms and have idiosyncratic component $\eta_{2}$. Marginal firms are labelled type 1 firms in Table 4 , and feature $\eta_{1}<\eta_{2}$. In equilibrium, the job value function of marginal firms turns negative in bad business (formally we have that $J^{11}<0$ and $J^{12}>0$ ). If there are no wasteful firing costs such firms naturally shed labour and declare bankruptcy. Bankrupt firms shed labour in bad times and in good times post a number of vacancies so as to satisfy their long run employment size. We calibrate marginal firms so that $\eta_{1}=-0.26$. The corresponding value functions, or the results of the functional equation 4 , yields values $J^{11}=0.5$ and $J^{12}=-0.2$. The latter condition ensures entry and exit in equilibrium.

Note that the marginal firms are naturally small firms, in line with the basic facts provided above. In our simulation, the long run employment of these firms amounts to only 1 percent of the size of incumbent firms. The most important parameter to calibrate is $m^{1}$ since it regulates the size of employment and vacancy fluctuations induced by firm entry and exit $\left(m^{1} l^{1}\right)$. From the macroeconomic standpoint the constraint on $m^{1}$ is provided by the employment loss accounted for by firm exit. Such measure does not exceeds 2 percent of total employment. Since bankruptcy in the model takes place only when the macroconditions change, the relevant statistics is not the average employment loss induced by bankruptcy (which in the simulated data would be very small) but rather the maximum loss.

Further, with respect to the calibration of Table 4, in the new set of simulation it is necessary to reduce the size of the aggregate shocks $p_{1}$ and $p_{2}$ so as to obtain an aggregate standard deviation around 2 percent, as in the U.S. data. These values are reported in the bottom of Tables 5 and 6 .

Table 5 reports the results of the simulations. The hiring and firing induced by the entry and exit of these small firms increases the amplification power of the model. The standard deviation of the vacancy unemployment ratio increases to 0.07 , and now accounts for almost 20 percent of the total amplification of productivity shocks displayed in the data. Table 5 shows that the maximum amount of job losses accounted for bankruptcy displayed in Table 5 amounts to some 2 percent of the total labour force. The presence 
of bankruptcy works mainly through the standard deviation of unemployment, which appears to increase substantially with respect to the simulations of Table in 4 . The results of Table 5 show that explicitly considering bankruptcy by marginal firms double the propagation power of the model .

Table 5: Bankruptcy Simulation

\begin{tabular}{|c|c|c|c|c|c|c|}
\hline \multicolumn{7}{|c|}{$\begin{array}{l}\text { No hiring Freeze; Bankruptcies } \\
\mathrm{m} 1=0.1100 ; \mathrm{m} 2=0.0200\end{array}$} \\
\hline & & $u$ & $v$ & $v / u$ & $f$ & $p$ \\
\hline \multirow{2}{*}{\multicolumn{2}{|c|}{ Standard Deviation }} & 0.0438 & 0.0277 & 0.0682 & 0.0460 & 0.0215 \\
\hline & & $(0.0084)$ & $(0.0055)$ & $(0.0130)$ & $(0.0055)$ & $(0.0087)$ \\
\hline \multirow{2}{*}{\multicolumn{2}{|c|}{ Autocorrelation }} & 0.8557 & 0.8674 & 0.8636 & 0.8823 & 0.8376 \\
\hline & & $(0.0208)$ & $(0.0320)$ & $(0.0246)$ & $(0.0286)$ & $(0.0248)$ \\
\hline \multirow[t]{9}{*}{ Correlation } & $\mathrm{u}$ & 1 & -0.8030 & -0.9697 & -0.9982 & -0.8022 \\
\hline & & & $(0.0424)$ & $(0.0084)$ & $(5.2210 \mathrm{e}-004)$ & $(0.0422)$ \\
\hline & $\mathrm{v}$ & & 1 & 0.9239 & 0.8218 & 0.9990 \\
\hline & & & & $(0.0164)$ & $(0.0377)$ & $(6.1905 \mathrm{e}-004)$ \\
\hline & $\mathrm{v} / \mathrm{u}$ & & & 1 & 0.9762 & 0.9230 \\
\hline & & & & & $(0.0062)$ & $(0.0162)$ \\
\hline & $\mathrm{f}$ & & & & 1 & 0.8188 \\
\hline & & & & & & $(0.0374)$ \\
\hline & $\mathrm{p}$ & & & & & 1 \\
\hline \multicolumn{7}{|l|}{$\gamma=0.7700$} \\
\hline \multicolumn{7}{|l|}{$p^{2}=0.0300 ; p^{1}-0.0300$} \\
\hline \multicolumn{7}{|c|}{ Average Job Finding Rate $=1.3397$} \\
\hline \multicolumn{7}{|c|}{ Elasticity of $v / u$ with respect to $p=3.1713$} \\
\hline \multicolumn{7}{|c|}{ Maximum Job Loss by Bankruptcy $=0.0202$} \\
\hline \multicolumn{7}{|c|}{ Standard errors in parentheses } \\
\hline Source: Authors calculat & & & & & & \\
\hline
\end{tabular}

\subsection{Simulation with Hiring Freeze}

The process of firm entry and exit modeled above suggests that the value of business in marginal firms fluctuates between $J^{11}=0.5$ and $J^{12}=-0.2$. This implies that a wasteful firing costs of only 20 percent of average productivity is sufficient to generate a hiring freeze. In what follows, we simulate the model under a hiring freeze by assuming that such admittedly small firing costs exist in the economy.

The simulations in the case of hiring freeze is reported in Table 6. A hiring freeze acts mainly through the behavior of vacancies, so that their explicit consideration should increase the dynamic response of vacancies to productivity shocks. This is what we find in Table 6 . The variability of the vacancy unemployment ratio accounted by the model increases to 0.077 , accounting almost for 20 percent of the variability in the data. Note that in the simulations proposed the marginal firms, albeit small, are fairly numerous and account for some [17] percent of employment. In other words, some 17 percent of employment is employed in firms that 
shut down their entire vacancy posting in bad times.

In the case of hiring freeze it is more difficult to calibrate the number of marginal firms. As Shimer (2005b) points out, "most contractions in employment are achieved by firms choosing to hire fewer workers", but there is no direct evidence for the size of this effect. As a matter of exercise, the number of marginal firms experiencing a hiring freeze can be increased substantially, and in Table 7 is as high as 40 percent of total employment. In such extreme case, the model is able to account for 35 percent of the total amplification displayed by U.S. data.

Table 6: Hiring Freeze Simulation

\begin{tabular}{|c|c|c|c|c|c|c|}
\hline \multicolumn{7}{|c|}{$\begin{array}{l}\text { Hiring Freeze; No Bankruptcies } \\
\mathrm{m} 1=0.1200 ; \mathrm{m} 2=0.0200\end{array}$} \\
\hline & & $u$ & $v$ & $v / u$ & $f$ & $p$ \\
\hline \multirow{2}{*}{\multicolumn{2}{|c|}{ Standard Deviation }} & 0.0285 & 0.0548 & 0.0779 & 0.0310 & 0.0213 \\
\hline & & $(0.0056)$ & $(0.0100)$ & $(0.0144)$ & $(0.0100)$ & $(0.0060)$ \\
\hline \multirow[t]{2}{*}{ Autocorrelation } & & 0.9787 & 0.8760 & 0.9169 & 0.8824 & 0.9514 \\
\hline & & $(0.0057)$ & $(0.0224)$ & $(0.0173)$ & $(0.0213)$ & $(0.0171)$ \\
\hline \multirow[t]{9}{*}{ Correlation } & $\mathrm{u}$ & 1 & -0.7218 & -0.8727 & -0.9931 & -0.7246 \\
\hline & & & $(0.0219)$ & $(0.0159)$ & $(0.0019)$ & $(0.0217)$ \\
\hline & $\mathrm{v}$ & & 1 & 0.9677 & 0.7819 & 0.9998 \\
\hline & & & & $(0.0018)$ & $(0.0148)$ & $(8.1558 \mathrm{e}-005)$ \\
\hline & $\mathrm{v} / \mathrm{u}$ & & & 1 & 0.9126 & 0.9686 \\
\hline & & & & & $(0.0099)$ & $(0.0018)$ \\
\hline & $\mathrm{f}$ & & & & 1 & 0.7829 \\
\hline & & & & & & $(0.0149)$ \\
\hline & $\mathrm{p}$ & & & & & 1 \\
\hline \multicolumn{7}{|c|}{ Standard errors in parentheses } \\
\hline \multicolumn{7}{|l|}{$\gamma 0.6000$} \\
\hline \multicolumn{7}{|l|}{$\eta_{1}-0.2600$} \\
\hline \multicolumn{7}{|l|}{$p^{2} 0.0290 ; p^{1}-0.0290$} \\
\hline \multicolumn{7}{|c|}{ Average Job Finding Rate 1.4286} \\
\hline \multicolumn{7}{|c|}{ Elasticity of $v / u$ with respect to $p 3.6579$} \\
\hline \multicolumn{7}{|c|}{ Maximum employment by firms that freeze hiring 0.1763} \\
\hline Source: Authors calculat & & & & & & \\
\hline
\end{tabular}

\section{Discussion and Literature Review}

The ability of the matching model of unemployment to account for the business cycle properties of the U.S. labour market has sparked a large open debate in the macroeconomics of the labour market. Shimer calibration showed that the $M P$ model accounts for only 10 percent of the total variability of the vacancy unemployment ratio. He claims that such inability is linked to the wage variability of the Nash Bargaining wage used in the standard model. As he argues in his paper, following an increase in labor productivity 
Table 7: Extreme Hiring Freeze Simulation

\begin{tabular}{|c|c|c|c|c|c|c|}
\hline \multicolumn{7}{|c|}{$\begin{array}{l}\text { Hiring Freeze; No Bankruptcies } \\
\mathrm{m} 1=0.3600 ; \mathrm{m} 2=0.0200\end{array}$} \\
\hline & & $u$ & $v$ & $v / u$ & $f$ & $p$ \\
\hline \multirow[t]{2}{*}{ Standard Deviation } & & 0.0528 & 0.0998 & 0.1445 & 0.0578 & 0.0215 \\
\hline & & $(0.0096)$ & $(0.0162)$ & $(0.0240)$ & $(0.0162)$ & $(0.0103)$ \\
\hline \multirow[t]{2}{*}{ Autocorrelation } & & 0.9770 & 0.8685 & 0.9111 & 0.8779 & 0.9495 \\
\hline & & $(0.0067)$ & $(0.0263)$ & $(0.0215)$ & $(0.0244)$ & $(0.0152)$ \\
\hline \multirow[t]{9}{*}{ Correlation } & u & 1 & -0.7678 & -0.8960 & -0.9923 & -0.7732 \\
\hline & & & $(0.0197)$ & $(0.0143)$ & $(0.0021)$ & $(0.0192)$ \\
\hline & $\mathrm{v}$ & & 1 & 0.9724 & 0.8287 & 0.9998 \\
\hline & & & & $(0.0016)$ & $(0.0114)$ & $(3.9768 \mathrm{e}-005)$ \\
\hline & $\mathrm{v} / \mathrm{u}$ & & & 1 & 0.9355 & 0.9742 \\
\hline & & & & & $(0.0072)$ & $(0.0016)$ \\
\hline & $\mathrm{f}$ & & & & 1 & 0.8321 \\
\hline & & & & & & $(0.0112)$ \\
\hline & $\mathrm{p}$ & & & & & 1 \\
\hline \multicolumn{7}{|c|}{ Standard errors in parentheses } \\
\hline \multicolumn{7}{|l|}{$\gamma=0.6600$} \\
\hline \multicolumn{7}{|l|}{$\eta_{1}=-0.2600$} \\
\hline \multicolumn{7}{|l|}{$p^{2}=0.0290 ; p^{1}=-0.0290$} \\
\hline \multicolumn{7}{|c|}{ Average Job Finding $\mathrm{Rate}=1.4342$} \\
\hline \multicolumn{7}{|c|}{ Elasticity of $v / u$ with respect to $p=6.7283$} \\
\hline \multicolumn{7}{|c|}{ Maximum employment by firms that freeze hiring $=0.3861$} \\
\hline Source: Authors calculat & & & & & & \\
\hline
\end{tabular}

vacancy posting increases, but "the increase in hiring also shorten unemployment duration, raising workers' threat point in wage bargaining, and therefore raising the expected present value of wages in new jobs. Higher wages absorb most of the productivity increase, eliminating the incentive for vacancy creation. As a result, fluctuations in labor productivity have little impact on the unemployment, vacancy, and job finding rates".

Hall (2005) finds that a rigid wage, not conditioned on the aggregate state and consistent with the bargaining set can explain the volatility of unemployment given quantitative specification of the other elements of the model. More recently Mortensen and Nagypal (2005) argue that a fixed wage is not the solution to the low amplification power of the model. The key difficulty for matching the vacancy unemployment ratio is a large difference between labor productivity and the wage implied by the standard model. The easiest way to show this key result is to consider the simplest matching model without aggregate shocks and a fixed wage (See Appendix and Mortensen and Nagypal, section $3.4^{3}$ ). The elasticity of the vacancy unemployment rate

\footnotetext{
${ }^{3}$ In the appendix we also show that a generalization of our model with vacancy costs that take the form $c(v)=c_{0}+c v$ converges to the same baseline matching model when the $c \rightarrow 0$,
} 
to productivity $p$ is

$$
\varepsilon_{\theta, p}=\frac{p}{\alpha(p-w)}
$$

where $\alpha$ is the elasticity of the matching function and $w$ is the fixed wage. This suggests that the size of $p-w$ is a key parameter in this simple model, and only wages very close to the productivity can dramatically increase this elasticity. Indeed, $\varepsilon_{\theta, p}$ tends to infinity as the wage tends to average productivity. Manovksii and Hagedorn (2005) were the first to point out that a wage very close to productivity would perfectly match the required elasticity. They calibrated $(p-w) / w$ to be around 3 percent of employment on the basis of the average profit rate in the U.S. economy and their calibration match the required elasticity. In general it is far from obvious that one can use $p-w$ as the profit rate, since the model has no capital costs and other factors.

The spirit of this paper, in relation to the debate in the literature outlined above, is the focus on firm heterogeneity. Our results can be interpreted as follows. There is more than one type of firm, and alongside stable firms, which behave very similarly to those modeled in the standard model, there is a marginal fringe of firms whose vacancy posting behavior is very volatile. For such marginal firms, whose nature of operation changes dramatically between good and bad times, the ratio $p /(p-w)$ is indeed very small, and thus contributes substantially to increase aggregate volatility and the model's ability to match the data. Firms who go bankrupt and firms that experience hiring freeze must necessarily act on a margin for which the profit rate is very small. The composition effect between these firms can be important for the macroeconomy.

These claims can be made more formal by considering the elasticity of the vacancy unemployment calculated in our model. Recall that the definition of the job filling rate can be expressed (neglecting any $j$ and time index) as

$$
q=\gamma^{-\alpha} \theta^{-\alpha}
$$

where $\theta$ is market tightness or the vacancy unemployment ratio $\frac{V}{U}$. Using the steady definition of equation 9 one has

$$
\rho \gamma^{-(1+\alpha)} \theta^{-(1+\alpha)}+\gamma^{-2 \alpha} \theta^{-2 \alpha}=\frac{\rho c(r+\rho)}{\sum_{i} m^{i}\left[p+\eta^{i}-w\right]}
$$

The definition of the elasticity of the matching function with respect to aggregate productivity $p$ is $\varepsilon_{\theta, p}=\frac{\partial \theta}{\partial p} \frac{p}{\theta}$ so that its analytic expression reads

$$
\begin{aligned}
\varepsilon_{\theta, p} & =h(\theta) \frac{p}{(p-w)+\frac{\Sigma_{i} m^{i} \eta^{i}}{\Sigma_{i} m^{i}}} \\
h(\theta) & =\frac{\rho \gamma^{-(1+\alpha)} \theta^{-\alpha}+\gamma^{-2 \alpha} \theta^{-2 \alpha-1}}{\rho(1+\alpha) \gamma^{-(1+\alpha)} \theta^{-\alpha}+2 \alpha \gamma^{-2 \alpha} \theta^{(-2 \alpha-1)}}
\end{aligned}
$$

In our baseline simulation with $I=1$ and $\eta^{2} \simeq 0$. The average value of $\theta$ is around 12 , so that simple substitution for the calibrated statistics above gives a value of the elasticity equal to 2.6. Such value, albeit 
larger than the simulated value of Table 4, shows that the steady state appromixation of the elasticity is quantitatively relevant.

Consider the model with only two type of firms that we have solved. While stable firms have $\eta^{2} \simeq 0$ marginal firms that are close to bankruptcy are such that $\eta^{1} \simeq w-p$. This implies that

$$
\varepsilon_{\theta, p} \simeq\left\{\begin{array}{cl}
h\left(\theta^{j}\right) \frac{p^{j}}{\left(p^{j}-w\right)\left(1-\frac{m^{1}}{m^{1}+m^{2}}\right)} & \text { if } p^{j}=p^{2} \\
h\left(\theta^{j}\right) \frac{p}{(p-w)} & \text { if } p^{j}=p^{1}
\end{array}\right.
$$

In this approximation it is clear that marginal firms in good times can increase substantially the amplification power of the model. Such amplification power, captured by the fraction $\frac{m 1}{m 1+m 2}$ depends on their relative size, and it is thus not surprising that the elasticity increase most in the extreme hiring freeze scenario. In the case of bankruptcy, where we calibrate the statistics $m^{1} /\left(m^{1}+m^{2}\right)$ to be 0.84 the elasticity in good times increase by a multiplier factor equal to 6 . Note, however, that the the overall elasticity depends also on its value in bad times and on the function $h\left(\theta^{j}\right)$, which is negatively related to $\theta$. This latter effects works in the opposite direction and tends to reduce the estimated elasticity. Further, note that the elasticity obtained by the analytical expression tends to be larger than the one obtained by the numerical simulation. This difference is linked to the slow downsizing of employment toward the steady state value in the simulations, while the elasticity assumed above is valid when the economy is already in steady state.

By focussing on firm heterogeneity, the paper has not dealt with wage determination issues. Even though wage variability is not the key determinants of unemployment dynamics, as we argued above, the fixed wage assumed in this paper can be hard to swallow. Focusing on a static version of the paper, the appendix shows that it is possible to obtain a full general equilibrium with endogenous wage, where the firm wage is obtained by rent sharing.

\section{Conclusion}

The paper has proposed a matching model of unemployment with firms active along both the intensive and extensive margin. In the standard model of unemployment, firms are not well defined and there is no distinction between firms and jobs. In the model we propose a convex cost for vacancy posting ensures that firms have a well defined long run position. On the intensive margin workers quits the firm at an exogenous attrition rate, and firms continuously post new vacancies. The steady state version of the model delivers predictions that are very similar to those of the standard matching model.

With aggregate productivity shocks, the model can easily generate job flows on the extensive margins of firm entry and exit. The paper characterizes a hiring freeze and a bankruptcy. Hiring freeze is experienced by those firms that shut down their vacancy posting behavior in adverse business conditions, and let employment downsizing be governed by workers' natural attrition. Bankrupt firms leave the market altogether 
in the face of adverse shocks. The paper has shown that the modeling of these phenomena has aggregate consequences. The quantitative exercise in the paper has shown that considering these phenomena can increase the responsiveness of the vacancy unemployment fluctuations up to 30 percent of the total variability observed in U.S. data.

\section{Appendix:}

\section{.1 Comparative Static of the Steady State Equilibrium}

The expression for $q^{j}$ can be written as

$$
\left(q^{j}\right)^{\frac{1+\alpha}{\alpha}}=\frac{\rho-k^{j}\left(q^{j}\right)^{2}}{\gamma k^{j} \rho}
$$

$\frac{\partial q^{j}}{\partial k^{j}}<0$ Differentiating with respect to $k^{j}$ one has

$$
\left[\left(\frac{1+\alpha}{\alpha}\right)\left(q^{j}\right)^{\frac{1}{\alpha}}+2 \frac{q^{j}}{\gamma \rho}\right] \frac{\partial q^{j}}{\partial k^{j}}=\frac{-2 \gamma \rho^{2}}{\left(\gamma k^{j} \rho\right)^{2}}
$$

$\frac{\partial q^{j}}{\partial \gamma}<0$. Differentiating with respect to $\gamma$ one has

$$
\left[\left(\frac{1+\alpha}{\alpha}\right)\left(q^{j}\right)^{\frac{1}{\alpha}}+2 \frac{q^{j}}{\gamma \rho}\right] \frac{\partial q^{j}}{\partial \gamma}=\frac{-\left[\rho-k^{j}\left(q^{j}\right)^{2}\right] k^{j} \rho}{\left(\gamma k^{j} \rho\right)^{2}}
$$

Since $\gamma$ measures the size of frictions

$\frac{\partial q^{j}}{\partial \alpha}>0$. Differentiating with respect to $\alpha$ one has

$$
-\frac{1}{\alpha^{2}}\left(q^{j}\right)^{\frac{1}{\alpha}+1}+\left(\frac{1}{\alpha}+1\right)\left(q^{j}\right)^{\frac{1}{\alpha}} \frac{\partial q}{\partial \alpha}=-k^{j} 2 q^{j} \frac{\partial q}{\partial \alpha}
$$

$\frac{\partial q^{j}}{\partial \rho}>0$ Differentiating with respect to $\rho$ one has

$$
\left[\left(\frac{1+\alpha}{\alpha}\right)\left(q^{j}\right)^{\frac{1}{\alpha}}+2 \frac{q^{j}}{\gamma \rho}\right] \frac{\partial q^{j}}{\partial \rho}=\frac{\gamma\left(k^{j}\right)^{2}\left(q^{j}\right)^{2}}{\left[\gamma k^{j} \rho\right]^{2}}
$$

\section{.2 Deriving the Fundamental Differential Equation}

$$
1-\sum_{i} m^{i} l_{t}^{i j}=\gamma\left(q_{t}^{j}\right)^{\frac{1}{\alpha}+1} k^{j}
$$

and taking the time derivative one has that

$$
-\sum_{i} m^{i} l_{t}^{i j}=\gamma k^{j}\left(q_{t}^{j}\right)^{\frac{1}{\alpha}} \dot{q}_{t}^{j}
$$

Making use of the definition of employment dynamics $i_{t}^{i j}$ at the firm level it follows that

$$
\rho \sum_{i} m^{i} l_{t}^{i j}-q_{t}^{j} \sum_{i} m^{i} v_{t}^{i j}=\gamma k^{j}\left(q_{t}^{j}\right)^{\frac{1}{\alpha}} \dot{q}_{t}^{j}
$$

And using equation 14 and the optimal vacancy posting $v_{t}^{i j}=q_{t}^{j} \frac{J_{t}^{i j}}{c}$

$$
\rho\left[1-\left(q_{t}^{j}\right)^{\frac{1}{\alpha}+1} k^{j} \gamma\right]-\left(q_{t}^{j}\right)^{2} k^{j}=\gamma k^{j}\left(q_{t}^{j}\right)^{\frac{1}{\alpha}} \dot{q}_{t}^{j}
$$

which can be written as

$$
\left(q_{t}^{j}\right)^{\frac{1}{\alpha}} \dot{q}_{t}^{j}+\frac{1}{\gamma}\left(q_{t}^{j}\right)^{2}-\frac{\rho\left[1-\left(q_{t}^{j}\right)^{\frac{1}{\alpha}+1} k^{j} \gamma\right]}{\gamma k^{j}}=0
$$




\section{.2.1 Baseline Matching Model with Exogenous Wage}

The matching function is indicated with $q(\theta)$ The value function of a vacancy and a filled job read

$$
\begin{aligned}
r V & =-c_{0}+q(\theta)[J-V] \\
(r+\rho) J & =p-w+\rho V
\end{aligned}
$$

so that free entry $(V=0)$ implies

$$
\frac{c_{0}}{q(\theta)}=\frac{p-w}{r+\rho}
$$

Implicitly differentiating with respect to $\theta$ one has

$$
\alpha(\theta) \frac{(p-w)}{\theta} \frac{\partial \theta}{\partial p}=1
$$

where $\alpha(\theta)$ is the absolute value of the elasticity of $q$ with respect to $\theta$. The elasticity of $\theta$ with respect to $p$ reads

$$
\varepsilon_{\theta, p}=\frac{\partial \theta}{\partial p} \frac{p}{\theta}=\frac{p}{\alpha(\theta)(p-w)}
$$

Note that if the matching function is $q=\theta^{-\alpha} \alpha(\theta)=\alpha$.

\section{.3 Convergence of the Convex Model to a Baseline Matching Model}

One can easily show that the model of this paper nests the baseline matching model described above as a special case. Suppose that the marginal cost of vacancy posting take the form

$$
c(v)=c_{0}+c v
$$

where it is clear that throughout the paper we assumed that $c_{0}=0$. Assume, for simplicity that there is only one type of firm $(i=1)$ and that business conditions are stationary $(\lambda=0)$. Optimal vacancy posting in the representative firm reads

$$
\left(c_{0}+c v\right)=q J
$$

where $J=\frac{p-w}{r+\rho}$ as in the previous section. Aggregate consistency requires

$$
q^{-\frac{1}{\alpha}}=\frac{\gamma m V}{1-m l}
$$

which simplifies to

$$
q^{-\frac{1}{\alpha}}=\frac{\gamma \kappa q-c_{0}}{c-\frac{q^{2} \kappa}{\rho}+\frac{c_{0} q}{\rho}}
$$

where $\kappa=m J$. The previous equation is simply a generalization of equation 10 . By simple algebra the equation can be written as

$$
\left[\kappa-\frac{c_{o}}{q}\right]\left[\gamma q^{(1 / \alpha+1)}+\frac{q^{2}}{\rho}\right]=c
$$

Note that as $c \rightarrow 0$ the solution of the previous equation becomes

$$
m J=\frac{c_{o}}{q}
$$

which the standard matching model with linear vacancy costs. 


\section{.3.1 Elasticity in the Model with convex vacancy posting}

The job filling rate can be expressed as

$$
q=\gamma^{-\alpha} \theta^{-\alpha}
$$

where $\theta$ is market tightness, and using the steady definition of equation 9 one has

$$
\rho \gamma^{-(1+\alpha)} \theta^{-(1+\alpha)}+\gamma^{-2 \alpha} \theta^{-2 \alpha}=\frac{\rho}{\frac{c}{r+\rho} \sum_{i} m^{i}\left[p+\eta^{i}-w\right]}
$$

The definition of the elasticity of the matching function with respect to aggregate productivity $p$ is $\varepsilon_{\theta, p}=\frac{\partial \theta}{\partial p} \frac{p}{\theta}$ so that implicitly differentiating equation 13 with respect to $\theta$ one has

$$
-\left\{\rho(1+\alpha) \gamma^{-(1+\alpha)} \theta^{-\alpha}+2 \alpha \gamma^{-2 \alpha} \theta^{(-2 \alpha-1)}\right\} \frac{\partial \theta}{\partial p}=-\frac{\rho}{\frac{c}{r+\rho}} \frac{\sum_{i} m^{i}}{\sum_{i} m^{i i}\left[p+\eta^{i}-w\right]^{2}}
$$

and using again equation 13 one has

$$
\frac{\partial \theta}{\partial p}=\frac{\rho \gamma^{-(1+\alpha)} \theta^{-(1+\alpha)}+\gamma^{-2 \alpha} \theta^{-2 \alpha}}{\rho(1+\alpha) \gamma^{-(1+\alpha)} \theta^{-\alpha}+2 \alpha \gamma^{-2 \alpha} \theta^{(-2 \alpha-1)}} \frac{\Sigma_{i} m^{i}}{\Sigma_{i} m^{i}\left[p+\eta^{i}-w\right]}
$$

so that the elasticity reads

$$
\begin{aligned}
\varepsilon_{\theta, p} & =\frac{\rho \gamma^{-(1+\alpha)} \theta^{-\alpha}+\gamma^{-2 \alpha} \theta^{-2 \alpha-1}}{\rho(1+\alpha) \gamma^{-(1+\alpha)} \theta^{-\alpha}+2 \alpha \gamma^{-2 \alpha} \theta^{(-2 \alpha-1)}} \frac{p}{(p-w)+\frac{\Sigma_{i} m^{i} \eta^{i}}{\Sigma_{i} m^{i}}} \\
\varepsilon_{\theta, p} & =h(\theta) \frac{p}{(p-w)+\frac{\Sigma_{i} m^{i} \eta^{i}}{\Sigma_{i} m^{i}}}
\end{aligned}
$$

where

$$
h(\theta)=\frac{\rho \gamma^{-(1+\alpha)} \theta^{-\alpha}+\gamma^{-2 \alpha} \theta^{-2 \alpha-1}}{\rho(1+\alpha) \gamma^{-(1+\alpha)} \theta^{-\alpha}+2 \alpha \gamma^{-2 \alpha} \theta^{(-2 \alpha-1)}}
$$

\section{.4 The Model With Endogenous Wage}

We consider a static version of the model with only one type of firm. The value functions read

$$
\begin{aligned}
r A & =-c v+q(J-A) \\
r J & =p-w+\rho(A-J) \\
r W & =w+\rho(U-W) \\
r U & =z+\frac{v}{u} q(W-U)
\end{aligned}
$$

Free entry implies $A=0$ so that the stock of vacancies is determined by $c v=q J$. The surplus from the job is defined as

$$
S=J+W-A-U
$$

and we assume that the wage is set so that the worker gets a fraction $\beta$ of the total surplus. Using the fact that $A=0$ the surplus can be written as

$$
(r+\rho) S=p-z-r U
$$

so that substituting into the firm value function, using the fact that $J=(1-\beta) S$ one has that the wage solves

$$
w=(1-\beta) r U+\beta p
$$


exactly as was derived by Bertola and Garibaldi (2001). The expression of the firm in this case reads

$$
J=\frac{(1-\beta)(p-r U)}{r+\rho}
$$

Using the aggregate consistency over $q$ one has that

$$
q^{-\frac{1}{\alpha}}=\frac{\frac{\gamma m J q}{c}}{1-\frac{m J}{c \rho} q^{2}}
$$

which can be written as

$$
q^{\frac{1}{\alpha}+1}=\frac{\left(1-\frac{\Phi}{\rho}(p-r U)\right) q^{q}}{\gamma \Phi(p-r U)}
$$

where $\Phi=\frac{m(1-\beta)}{(r+\rho) c}$. Using the definition of the matching function, and the wage rule $(W-U=\beta S)$ one has

$$
r U=b+\gamma^{\frac{1}{\alpha}} q^{\frac{\alpha-1}{\alpha}} \beta\left(\frac{p-z-r U}{r+\rho}\right)
$$

The equilibrium is obtained by the intersection of the two functions 16 and 17 . One can easily show, through simple differentiation, that in equation $17 \frac{\partial r U}{\partial q}<0$ while in equation $16 \frac{\partial r U}{\partial q}>0$ so that and equilibrium exists.

\section{A References}

Bartelsman, E. Scarpetta, S. and F. Schivardi (2005) "Comparative Analysis of Firm Demographics and Survival: Micro-level Evidence for the OECD countries " Industrial and Corporate Change, Vol. 14, pp. 365-391, 2005.

Bertola, Giuseppe, and Caballero, R.J. "Cross-Sectional Efficiency and Labour Hoarding in a Matching Model of Unemployment", Review of Economic Studies 61 (1994), 435-457

Bertola, G. and Garibaldi, P. (2001) "Wages and the Size of Firms in Dynamic Matching Models" Review of Economic Dynamics

Business Employment Dynamics (2004) "Business Employment Dynamics: new data on gross job gains and losses", Monthly Labor Review April

Cahuc, P. Marque, F and Wasmer, E. "A Theory of Wages and Labor Demand with Intrafirm Bargaining and Matching Frictions" mimeo, University Paris I.

Cole, H. Rogerson, R. (1998) "Can the Mortensen Pissarides Matching Model Match the Business Cycle Facts" International Economic Review

Davis, S., Haltiwanger, J. and Schuh (1996) Job Creation and Job Destruction, MIT Press

Dunne, T., Roberts, M. Samuelson, L. (1989) "Patterns of Entry and Exit in the U.S. Manufacturing Sector" The Rand Journal of Economics, Vol. 19, No. 4 495-515.

Hagedorn, M and I. Manovskii (2005) "The Cyclical Behavior of Equilibrium Unemployment and Vacancies Revisited," working paper, U. of Pennsylvania 
Hall, R.E. (2005) "Employment Fluctuations with Equilbrium Wage Stickiness" American Economic Review 95 (March): 25-49

Mortensen, D. and C.A. Pissarides (1994) "Job Creation and Job Destruction" in the Theory of Unemployment, Review of Economic Studies, 61:397-415

Nagypal, E. Mortensen D. (2005) "More on Unemployment and Vacancy Fluctuations" IZA Discussion Paper num. 1765

Petrongolo, B. and Pissarides, C. "Looking into the Blacj Box: A Survey of the Matching Function" Journal of Economic Lietarture, 2001, 39(2) pp. 390-431

Pissarides, C. "Equilibrium Unemployment theory, 2nd ed. Cambridge, MA: MIT Press 2001

Pissarides, C. (1985) "Short-Run Equilibrium Dynamics of Unemployment, Vacancies, and Real Wages" American Economic Review, 75/4), pp. 676-90

Shimer, R. (2005a) "The Cyclical Behavior of Equilibrium Unemployment and Vacancies" American Economic Review 95 (march) 25-49

Shimer, R. (2005b) "Reassessing the ins and outs of unemployment" mimeo, University of Chicago. 